\title{
Caspase-2 deficiency accelerates chemically induced liver cancer in mice
}

\author{
S Shalini ${ }^{1}$, A Nikolic ${ }^{1}$, CH Wilson ${ }^{1}$, J Puccini ${ }^{1}$, N Sladojevic ${ }^{1}$, J Finnie ${ }^{2}$, L Dorstyn ${ }^{1}$ and S Kumar, ${ }^{*}$
}

Aberrant cell death/survival has a critical role in the development of hepatocellular carcinoma (HCC). Caspase-2, a cell death protease, limits oxidative stress and chromosomal instability. To study its role in reactive oxygen species (ROS) and DNA damageinduced liver cancer, we assessed diethylnitrosamine (DEN)-mediated tumour development in caspase-2-deficient $\left(\right.$ Casp2 $^{-1-}$ ) mice. Following DEN injection in young animals, tumour development was monitored for 10 months. We found that DEN-treated Casp2 $^{-/-}$mice have dramatically elevated tumour burden and accelerated tumour progression with increased incidence of HCC, accompanied by higher oxidative damage and inflammation. Furthermore, following acute DEN injection, liver injury, DNA damage, inflammatory cytokine release and hepatocyte proliferation were enhanced in mice lacking caspase-2. Our study demonstrates for the first time that caspase-2 limits the progression of tumourigenesis induced by an ROS producing and DNA damaging reagent. Our findings suggest that after initial DEN-induced DNA damage, caspase-2 may remove aberrant cells to limit liver damage and disease progression. We propose that Casp2 $^{--}$mice, which are more susceptible to genomic instability, are limited in their ability to respond to DNA damage and thus carry more damaged cells resulting in accelerated tumourigenesis.

Cell Death and Differentiation (2016) 23, 1727-1736; doi:10.1038/cdd.2016.81; published online 12 August 2016

The initiator caspase, caspase-2, has recently emerged as a tumour suppressor with loss of this protein being associated with increased lymphomagenesis in ATM-deficient mice and $E \mu-M y c$ transgenic mice, and MMTV/c-neu-driven mammary carcinoma. $^{1-4}$ Caspase-2 has been shown to protect cells from oxidative stress, DNA damage and genomic instability, and caspase-2 deficiency is linked to chromosomal instability and aneuploidy. ${ }^{1,5,6}$ However, currently little is known about the possible role of caspase-2 in carcinogenesis induced by ROS and DNA damage.

Hepatocellular carcinoma (HCC) is among the most common cancers and is the second leading cause of cancer-related deaths worldwide. ${ }^{7}$ Development of HCC is multifaceted progressing from DNA damage to dysplasia, adenoma development and malignant transformation of hepatocytes. ${ }^{7,8}$ The major risk factors of HCC include viral hepatitis, excessive alcohol consumption, carcinogens and metabolic diseases. ${ }^{7,8}$ Despite this, the molecular causes of the disease are relatively less understood. Diethylnitrosamine (DEN) is a DNA alkylating and ROS inducing carcinogen that is widely used as a model to study the progression of HCC in rodents. ${ }^{9,10}$ DEN treatment mimics the human disease by inducing DNA damage in proliferating hepatocytes of infant mice. ${ }^{9}$ Increases in the generation of ROS and accumulation of DNA damage can stimulate an inflammatory response and hyperproliferation that helps drive tumour progression. ${ }^{7-10}$ It has increasingly been recognised that apoptosis and compensatory proliferation are crucial for progression of certain cancers including HCC. ${ }^{11-13}$ While loss of apoptosis would indirectly favour proliferation, this is not universally true, for example loss of PUMA, or hepatocyte-specific deletion of Bid, impedes HCC by preventing compensatory proliferation. ${ }^{14-20}$

Metabolic state is another important regulator of HCC progression and there is increasing evidence that caspase-2 has a subtle role in regulating this process. ${ }^{21,22}$ Caspase-2 deficiency in mice results in metabolic perturbations and aged caspase-2 mice show increased oxidative stress and DNA damage. ${ }^{5,21,23}$ DEN-induced tumour formation involves the generation of DNA adducts, ${ }^{10}$ and human HCC is commonly associated with genomic instability. ${ }^{24}$ These observations, combined with the known tumour suppressor role in lymphoma and MMTV-driven mammary carcinoma, suggest a possible role of caspase-2 in HCC. Thus, we sought to explore whether caspase-2 deficiency would promote chemically induced hepatic carcinogenesis in liver. We observed that DEN-induced liver tumours in Casp2 ${ }^{-/-}$mice were consistently larger and more advanced than those in WT mice, providing the first evidence that caspase-2 deficiency has a role in ROS and DNA damaged mediated HCC.

\section{Results}

Caspase-2 deficiency causes increased incidence of HCC. Casp $2^{-/}$mice injected with DEN at 15 days old consistently showed enlarged livers with increased tumour burden compared with WT mice at 10 months post injection

\footnotetext{
${ }^{1}$ Centre for Cancer Biology, University of South Australia, Adelaide, SA 5000, Australia and ${ }^{2}$ SA Pathology and School of Medical and Veterinary Science, University of Adelaide, Adelaide, SA 5000, Australia

*Corresponding author: S Kumar, Centre for Cancer Biology, University of South Australia, Frome Road, Adelaide, SA 5000, Australia. Tel: +61 882223738; Fax: +61 882223162; E-mail: sharad.kumar@unisa.edu.au

Abbreviations: HCC, hepatocellular carcinoma; DEN, diethylnitrosamine; ROS, reactive oxygen species; ALT, alanine aminotransferase; AST, aspartate transaminase; LDH, lactate dehydrogenase; ALP, alkaline phosphatase; TUNEL, terminal deoxynucleotidyl transferase dUTP nick end labelling; PCNA, proliferating cell nuclear antigen; HMGB1, high-mobility group box 1

Received 11.1.16; revised 05.6.16; accepted 07.7.16; Edited by G Melino; published online 12.8.2016
} 
(Figures 1a and c). While all Casp2 ${ }^{-/}$mice injected with DEN formed tumours at 10 months, 2/11 DEN-injected WT mice were tumour free (Figure 1b). Histological analysis of livers from young (6-9 weeks) non-DEN-injected tumour free Casp $^{-/-}$mice had no abnormal liver morphology or perturbed hepatocyte nuclei. However, consistent with previous findings ${ }^{23}$ by 10 months of age all PBS-injected Casp2 ${ }^{-1-}$ mice displayed an increase in nuclear volume (karyomegaly) and binucleation (Supplementary Figure 1a and b).

In DEN-injected WT mice, livers were usually macroscopically normal with occasional protrusion of tumour nodules (Figure 1a). Microscopically, altered hepatic foci were often present (Supplementary Figure 1c). Foci were composed of hepatocytes generally resembling those found in adjacent unaffected hepatic parenchyma, but with a cytoplasmic tinctorial appearance ranging from eosinophilic, basophilic, clear or vacuolated (fatty change). Hepatocytes in tumour masses were generally well differentiated and resembled the tinctorial span found in hepatic foci. Mitoses were rare to absent. Tumour masses were usually well circumscribed, but frequently compressed the surrounding parenchyma, and were designated hepatocellular adenomas (HCAs) (Figure 1d and Supplementary Figure 1c).

Macroscopicaly, livers of Casp2 $2^{-/-}$mice often showed multiple tumour masses of varying size and colour (Figure 1a). Microscopically, these contained many hepatocytes with enlarged, hyperchromatic, atypical nuclei of round to ovoid, more elliptical, or sometimes lobulated, appearance, sometimes bi- or multinucleated, and often showed prominent nucleoli (Figure 1d and Supplementary Figure 1d-f). Mitotic figures were usually common and some were abnormal (Supplementary Figure 1e). These tumours were diagnosed as HCCs. Some of these neoplasms contained hepatocytes with numerous eosinophilic cytoplasmic inclusions (globular bodies) of varying size, which have been correlated with a reduced proliferation index (Supplementary Figure 1d). No metastasis was observed in any mice. We used Glypican 3 as a marker for $\mathrm{HCC}^{7}$ and observed positive staining in 5/7 DEN-injected Casp2 ${ }^{-/}$mice livers while none of the WT mice showed any positive reaction (Figure 1d).

Increased oxidative stress, liver damage and inflammation in Casp2 $^{-1}$ mice. DEN generates ROS and causes DNA damage, which contributes to the development of HCC. ${ }^{9,24}$ As Casp2 ${ }^{-1-}$ mice are more susceptible to oxidative stress-induced damage to lipids, DNA and protein, ${ }^{24,25}$ these parameters were measured in liver (Figures $2 a, b$ and $d$ ). While no difference in lipid peroxidation (MDA) was observed between WT and Casp2 ${ }^{-1-}$ DEN-injected mice (Figure 2a), protein carbonylation (Figure 2d) and 8-OHdG levels (Figure 2b) were significantly higher in DEN-injected Casp2 $^{-/}$mice, indicating greater oxidative protein and DNA damage. SOD activity increased in both groups after DEN injections but was significantly lower in the Casp2 ${ }^{-/}$ mice (Figure 2c). Serum analysis revealed elevation of liver function enzymes ALT and ALP in DEN-injected Casp2 ${ }^{-/}$ mice compared with WT (Figures $2 e$ and $f$ ), indicating increased liver damage. While cholesterol, HDL and LDL increased following DEN injection, no difference was observed between WT and Casp2 ${ }^{-1-}$ mice (Supplementary
Figure 2). Along with increased liver damage, IL6 levels were increased in DEN-injected mice and were significantly elevated in DEN-injected Casp2 ${ }^{-/}$mice compared with WT (Figure $2 \mathrm{~g}$ ). Increases in IL1 $\alpha$ and IL1 $\beta$ levels were also observed in DEN-injected Casp2 ${ }^{-/}$mice compared with WT (Figures $2 \mathrm{~h}$ and i).

Liver damage and inflammation is often accompanied by increases in hepatic cell death and proliferation. ${ }^{13}$ We used immunoblot analysis and TUNEL to determine levels of apoptosis in DEN-injected mice. Slightly increased cleavage of caspase-3 was observed by immunoblotting in DENinjected WT, but not in Casp2 ${ }^{-1}$ mice (Figure 3a). However, there was no difference in PARP cleavage or levels of PUMA (Figure $3 a$ ) or in the frequency of TUNEL-positive cells (Figure 3b). In addition, no difference in cleaved caspase-3 was detected by immunohistochemical analysis of liver sections (Supplementary Figure 3). Proliferation of hepatocytes as assessed by PCNA staining of DEN-injected livers was high in both WTand Casp2 $^{-/}$mice, but no difference was observed between genotypes (Figure 3c).

Altered metabolism and stress-response pathways in advanced stage Casp $^{-/}$tumours. We next investigated the contribution of altered metabolism and stress/DNA damage response pathways to the increased susceptibility of DEN-induced HCC in Casp2 ${ }^{-/}$mice. Activation of stressresponse pathways was analysed by immunoblotting with an increase in phospho-JNK being observed in Casp2 $^{-1-}$ mice along with a trend towards increased ERK activation (Figure 4 and Supplementary Figure 4).

Previous studies have reported altered metabolic profile in Casp $2^{-1}$ mice. $^{19}$ During the development of HCC and HCA, the activity of several enzymes involved in glycogen metabolism, oxidative pentose phosphate pathway and glycolysis is different. ${ }^{25}$ It is known that adenomas largely contain basophilic cells with high fat or glycogen content. ${ }^{25}$ In addition, G-6-Pase and ALPase activity increases as adenomas develop into carcinomas while G6PDH activity declines in carcinomas. ${ }^{25}$ DEN injection did not alter the levels of glycogen or G-6-P in WT or Casp2 ${ }^{-1}$ mice (Figures $5 \mathrm{a}$ and b). However, compared with WT, glycogen levels were lower in both PBS- and DEN-injected Casp2 ${ }^{-1-}$ mice and G-6-P was lower in DEN-injected Casp2 $^{-/-}$mice (Figures $5 \mathrm{a}$ and b). In addition, G6PDH activity was reduced in DEN-injected compared with PBS-injected Casp2 ${ }^{-/}$mice (Figure 5c). Another group of proteins that regulate metabolism and have been linked with DEN-induced HCC is Sirtuins. ${ }^{26-28}$ We therefore measured Sirt1 and 3 expression and activity. Sirt1 activity was reduced in DEN-treated Casp2 $^{-1-}$ mice, but not in WT (Figure 5d), whereas Sirt3 activity was significantly increased by DEN in WT mice but not in Casp2 $^{-1-}$ mice (Figure 5e). Surprisingly, an increase in total Sirt1 protein levels was detected in DEN-treated Casp2 $^{-1-}$ mice (Figure 5f). This may be a compensatory response from the decrease in Sirt1 activity. No differences in total Sirt3 protein levels were observed (Figure 5f). P53 is frequently inactivated (mutated) in HCC, impairing the DNA damage response. ${ }^{24}$ Therefore, we investigated p53 and p21 levels by immunoblotting. Total p53 protein levels were somewhat increased in DEN-treated WT 
a
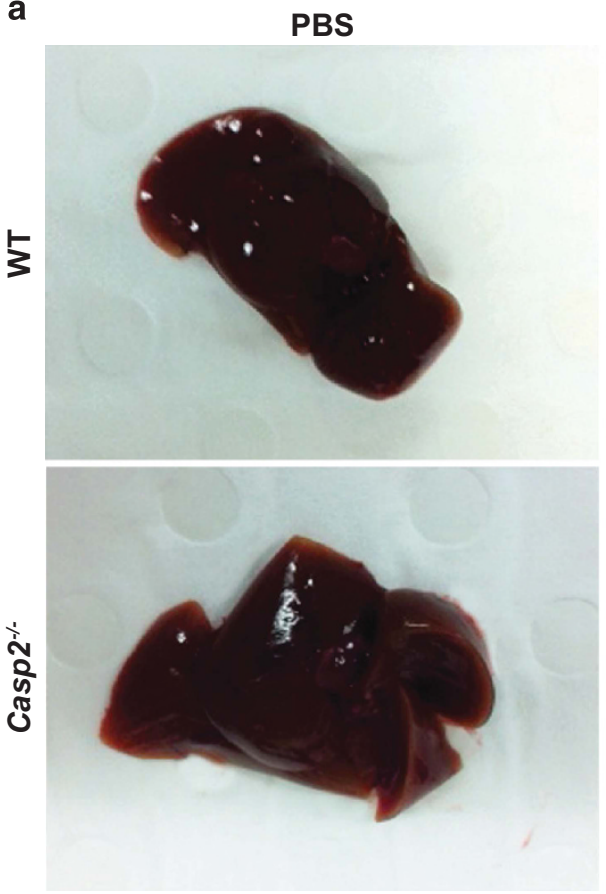

b

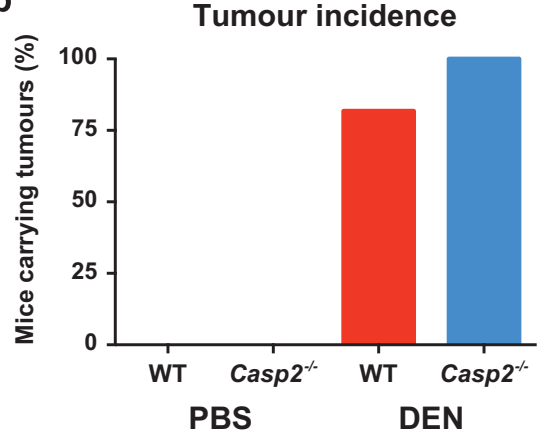

d
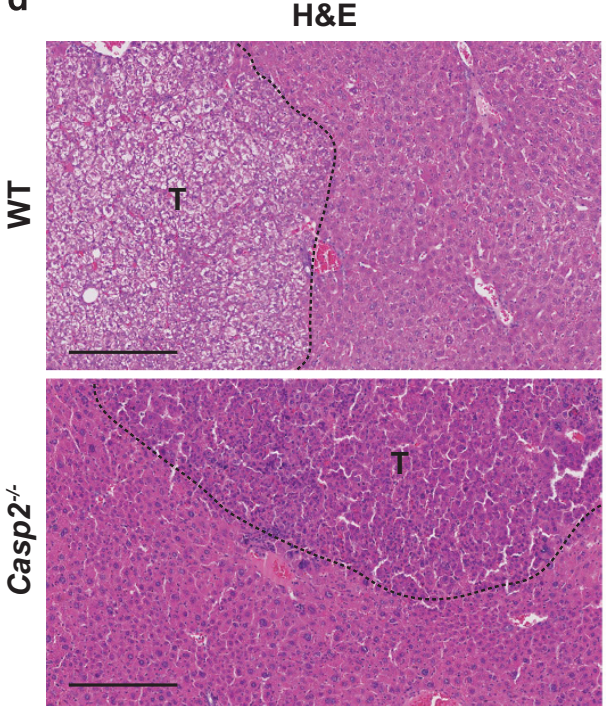

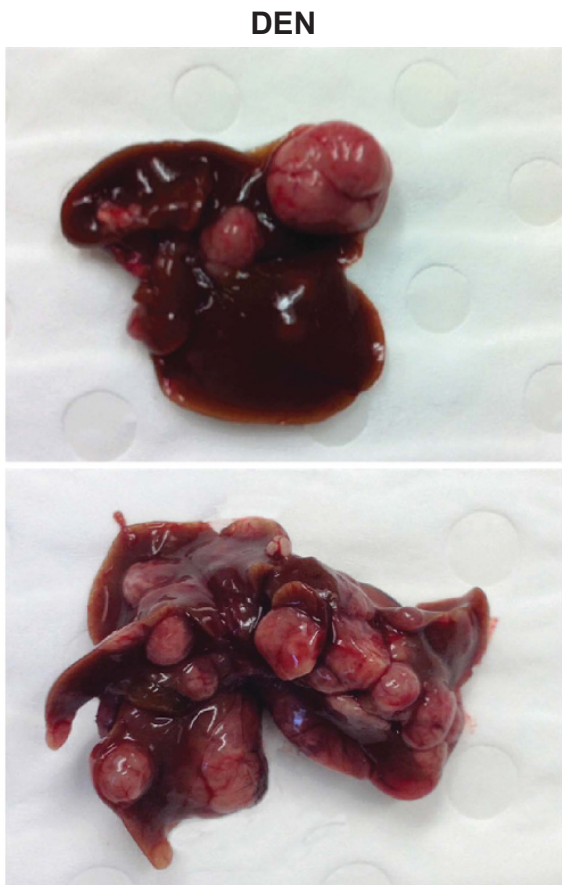

C
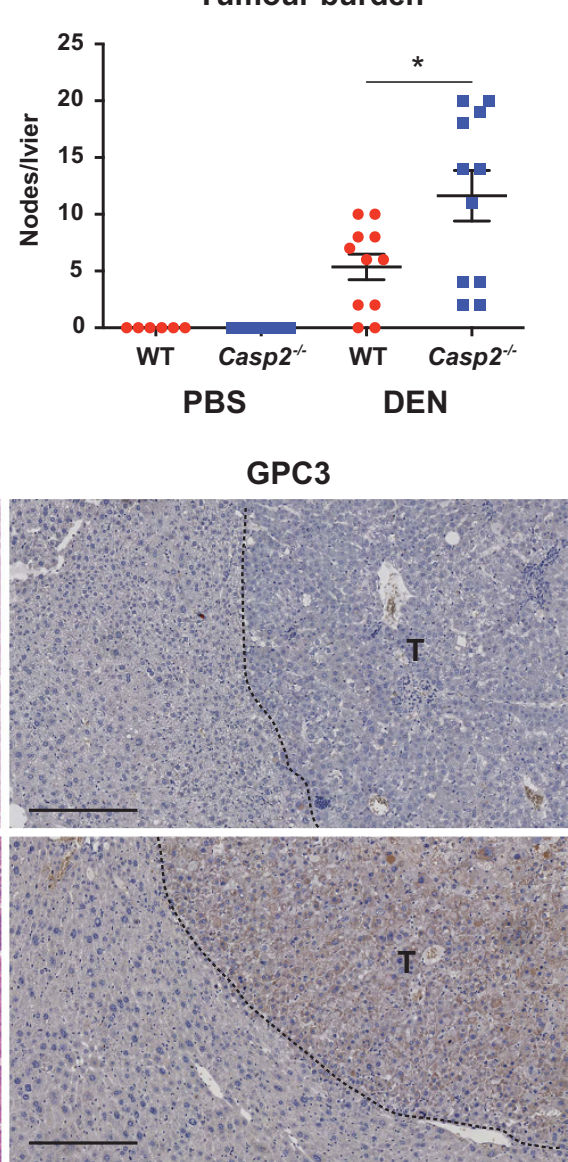

Figure 1 Loss of caspase-2 accelerates HCC development. (a) Macroscopic view of representative images of mice liver, 10 months after PBS/DEN administration. (b) Tumour incidence and (c) tumour burden in DEN-injected mice. Values are given as mean \pm S.E.M. ( $n=6$, PBS and $n=11$, DEN). Statistics were performed using Student's t-test: ${ }^{*} P<0.05$. (d) Representative haematoxylin and eosin-stained images of mice liver tumours and immunohistochemical staining for Glypican 3 , as a marker of $\mathrm{HCC}$ showing positive in Casp2 ${ }^{-/-}$mice, 10 months after PBS/DEN administration. Scale bar represents $250 \mu \mathrm{m}$. Tumour nodes outlined and labelled as 'T' 
a

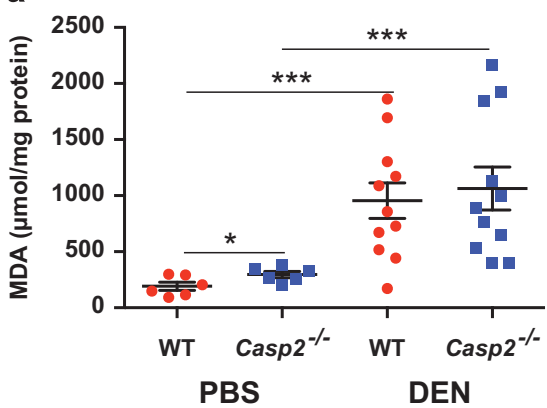

d
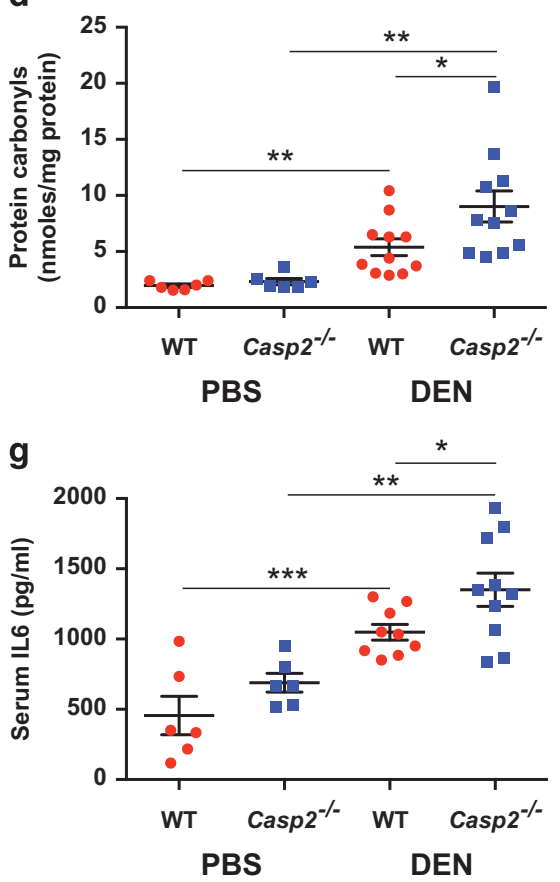

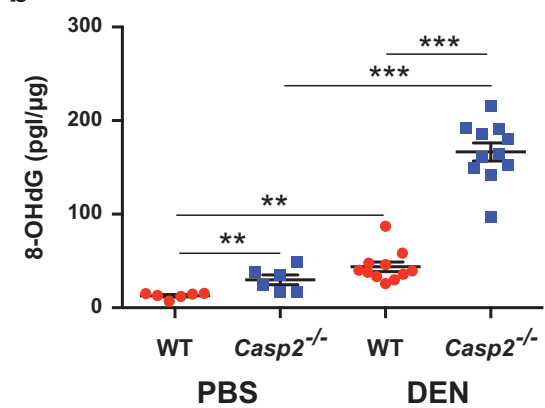

e

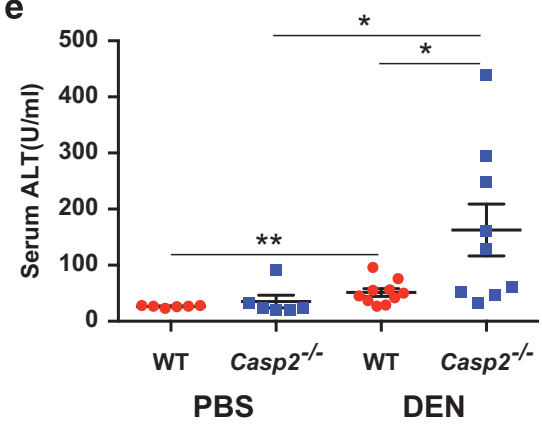

h

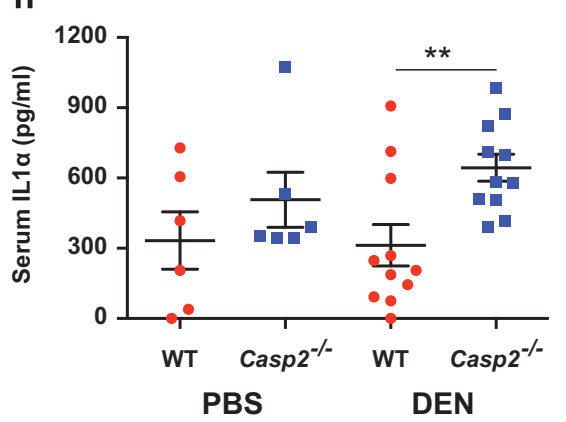

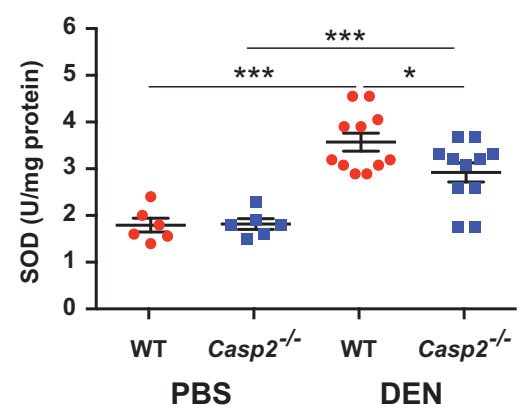

$\mathbf{f}$

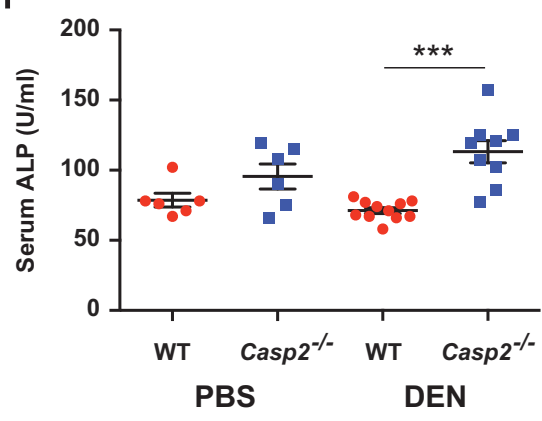

i

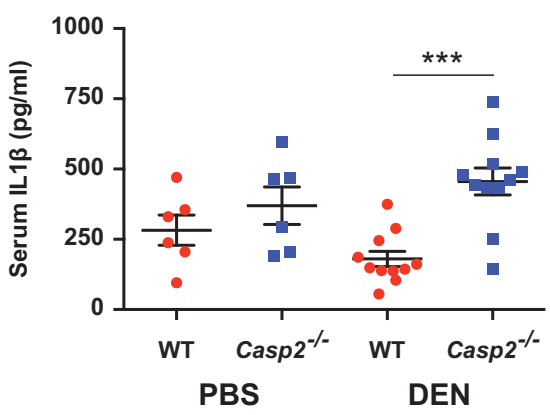

Figure 2 Casp2 $2^{-/}$mice have higher oxidative damage and inflammation. (a) Lipid peroxidation, (b) oxidatively modified DNA; 8-OHdG, (c) SOD (total) activity and (d) protein carbonyls were determined in mice liver lysates. (e) Alanine transaminase (ALT), (f) Alkaline phosphatase (ALP), (g) IL6, (h) IL1 $\alpha$ and (i) IL1 $\beta$ were measured in serum. Values are given as mean \pm S.E.M. $\left(n=6\right.$, PBS and $n=11$, DEN). Statistics were performed using Student's $t$-test. ${ }^{*} P<0.05,{ }^{* *} P<0.01$ and ${ }^{* \star *} P<0.001$

mice and were significantly higher in DEN-treated Casp2 $^{-/-}$ mice compared with WT as were p21 levels.

Increased cellular damage in the absence of cell death is responsible for proliferative advantage in Casp2 $^{-/}$mice. To further investigate the mechanisms that lead to increased tumour incidence and burden in $\mathrm{Casp}^{-/-}$mice, we carried out short-term DEN exposure. After $24 \mathrm{~h}$ DEN, little to no TUNEL-positive cells were observed in Casp2 $^{-1}$ mice liver compared with WT but at $48 \mathrm{~h}$ both WT and Casp2 ${ }^{-1-}$ mice displayed TUNEL-positive hepatocytes with no difference between genotypes (Figure 6a). Damage was localised to the central canal regions. $\mathrm{yH} 2 \mathrm{Ax}$ is a well-known marker for dsDNA breaks and $48 \mathrm{~h}$ after DEN injection, $\gamma \mathrm{H} 2 \mathrm{Ax}$ was increased in both WT and Casp2 ${ }^{-/-}$mice, with Casp2 $^{-/}$mice having significantly higher number of $\mathrm{yH} 2 \mathrm{Ax}$-positive cells compared with WT (Figure 6b). Notably, although reduced TUNEL reactivity was observed at $24 \mathrm{~h}$ in Casp2 $^{-1-}$ mice, pale necrotic centrolobular region was evident in both WT and Casp2 $^{-/}$mice (Supplementary Figure 5). PCNA staining was then performed on the same sections. At $48 \mathrm{~h}$ post DEN injection, there were significantly more PCNA-positive cells in the Casp2 $^{-1-}$ mice compared with WT mice (Figure 6c). To assess the extent of liver damage, we measured serum ALT and observed increased activity in Casp $^{-1}$ mice at $48 \mathrm{~h}$ (Figure 6d). Compared with WT, IL6 levels were increased in Casp2 $^{-1-}$ mice at 24 and $48 \mathrm{~h}$ and IL1 $a$ levels at $48 \mathrm{~h}$ after DEN injection (Figures $6 \mathrm{~g}$ and e). Furthermore, IL1 $\alpha$ and IL1 $\beta$ were further increased in DEN-injected Casp2 $^{-/}$mice at $48 \mathrm{~h}$ compared with $24 \mathrm{~h}$ (Figures $6 \mathrm{e}$ and $\mathrm{f}$ ).

Increased DNA damage in adult Casp2 $^{-/}$mice treated with DEN. In additional experiments, the effect of DEN was also studied by injecting $25 \mathrm{mg} / \mathrm{kg}$ DEN in 6-week-old mice. Mice were maintained for 1 year and then analysed for tumour development. None of the mice formed tumours. This 
a

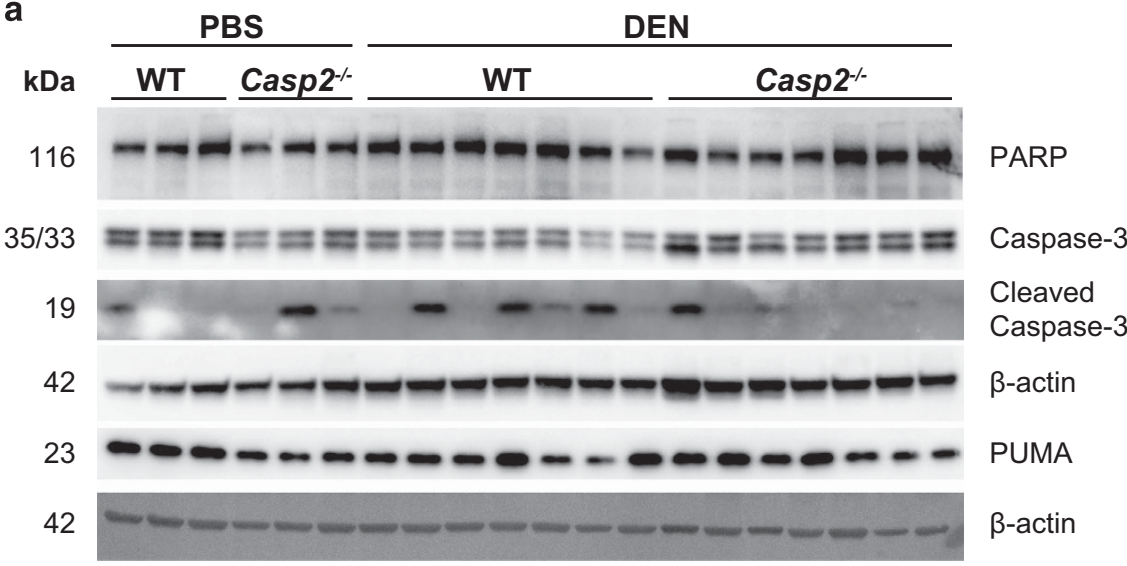

b
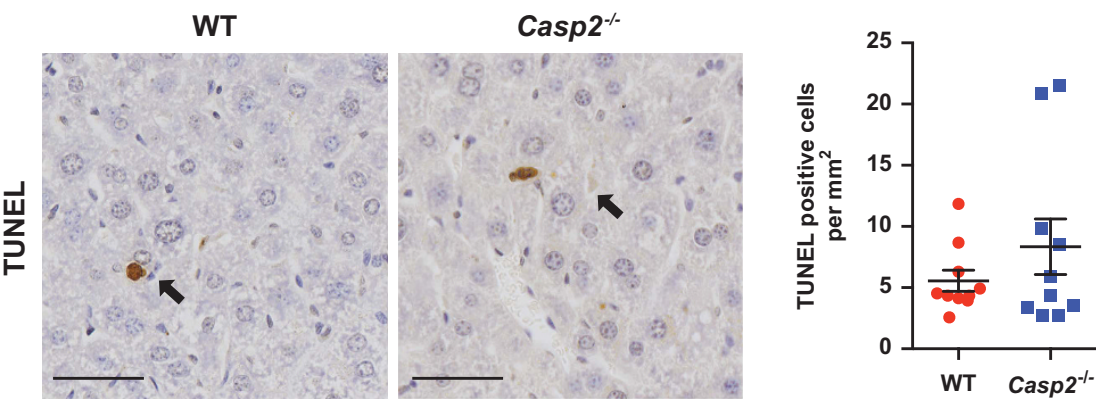

c
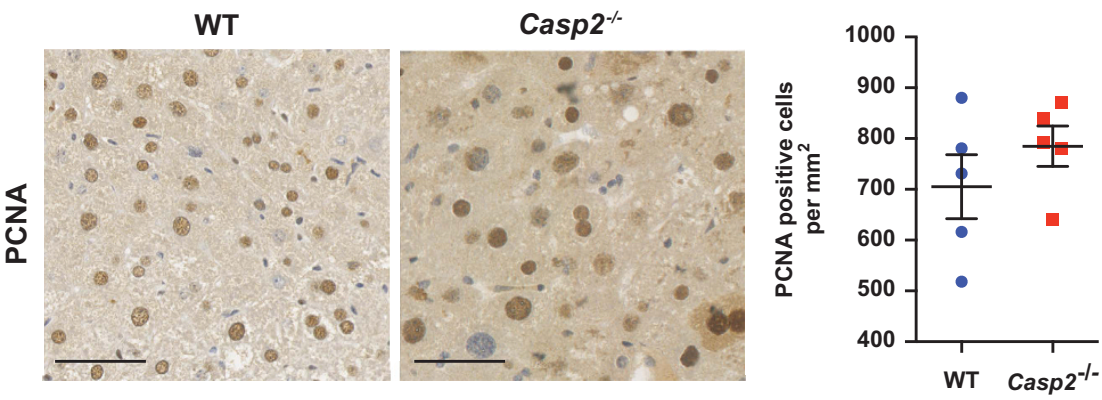

Figure 3 Casp2 ${ }^{-/}$mice display no difference in cell death or proliferation. (a) Representative western blots showing increased caspase-3 cleavage in DEN-injected WT mice. (b) Representative images of TUNEL-positive cells in mice liver 10 months after PBS/DEN administration. Scale bar represents $50 \mu \mathrm{m}$. (c) Immunohistochemical staining for PCNA, as a marker of cell proliferation showing high frequency of PCNA-positive hepatocytes in brown, 10 months following DEN exposure. Scale bar represents $50 \mu \mathrm{m}$

is consistent with the fact that a single DEN dose produces tumours when injected in infant mice when hepatocytes are proliferating. Consistent with previous findings, ${ }^{23}$ Casp2 ${ }^{-1-}$ mice showed significant karyomegaly, increased anisocytosis, presence of intranuclear vacuoles and bi/multinucleate cells, suggesting severe DNA damage and dysregulated cell cycling (Supplementary Figure 7a). TNFa and IL6 were also significantly higher in DEN-injected Casp2 ${ }^{-/-}$ mice (Supplementary Figure $7 \mathrm{~b}$ and $\mathrm{c}$ ). Consistent with mice injected at 15 days, an increase in ERK and JNK activation was also observed in DEN-injected Casp2 $^{-/-}$livers (Supplementary Figure 7d).

\section{Discussion}

In this study, we provide a direct evidence for caspase-2 in delaying DEN initiated liver tumours. We find higher DNA damage in Casp2 $^{-1}$ mice when exposed to DEN compared with WT mice. Casp2 $2^{-/-}$mice also had increased liver damage and formed aggressive HCCs.

Hepatocarcinogenesis is a multistep process that can be caused by a number of agents that ultimately lead to malignant transformation of hepatocytes. ${ }^{7-10,29}$ HCC induction by DEN is a commonly utilised mouse model. ${ }^{9,10} \mathrm{DEN}$ is an alkylating agent that induces DNA damage by reacting with nucleophiles such as DNA bases. ${ }^{9,10}$ Furthermore, DEN bioactivation involves the activity of P450 enzymes which produces ROS and results in oxidative stress. ${ }^{9,30}$ ROS-induced DNA, protein and lipid damage is known to contribute to hepatocarcinogenesis. $^{30-32}$ Single DEN dose causes HCC in $80-100 \%$ rodents in about $45-105$ weeks $^{33}$ with the sequential emergence of preneoplastic hepatic foci, HCAs and then $\mathrm{HCC}^{25}$ Casp2 $^{-/}$mice formed carcinomas after 10 months of DEN injections while the majority of tumours in 


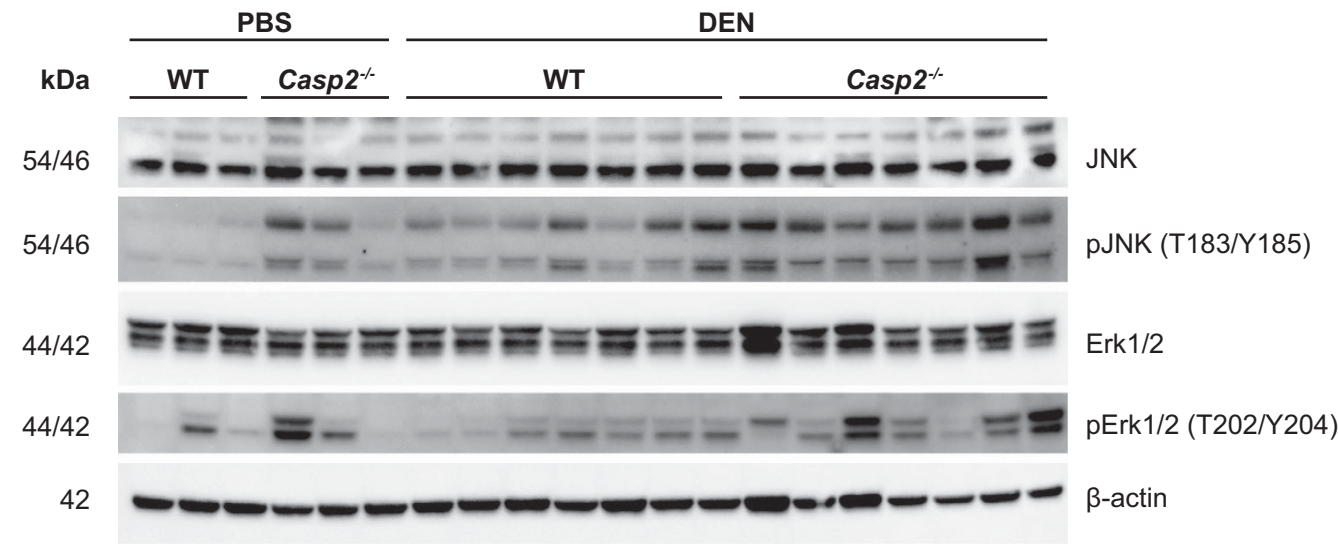

Figure 4 Casp2 $2^{-/}$mice display stress-induced JNK activation. Immunoblot analysis of MAPK activation pathway. Activation of the JNK stress-response pathway was significantly increased in Casp2 $^{-1}$ mice. There was also a trend towards ERK pathway activation

WT mice were classified as adenomas, suggesting that tumours in Casp2 ${ }^{-/-}$mice were more advanced.

One reason for the advanced tumorigenic state may be higher ROS levels in Casp2 ${ }^{-/-}$mice leading to increased oxidative stress-induced DNA damage. We have shown earlier that Casp2 $^{-/}$mice experience excessive oxidative stress with ageing and oxidative stress response $e^{5,23}$ and here again show increased susceptibility to more oxidative DNA and protein damage after DEN injection. Sirtuins contribute to the response to oxidative stress and the lower Sirt1 and Sirt3 activities in DEN-injected Casp2 ${ }^{-/-}$mice may in part contribute to increased susceptibility to DEN-induced damage. Sirt3 has several substrates involved in oxidative stress response such as MnSOD. ${ }^{34}$ Consistent with the lack of increased Sirt3 activity as observed in WT, SOD activity was lower in DEN-injected Casp2 ${ }^{-/-}$mice, which is likely to contribute to higher oxidative damage in this group. Further, higher serum ALT levels and ALP levels indicate increased liver injury in this group of mice.

A number of signalling pathways have been implicated in DEN-induced liver carcinogenesis, and stress activated JNK expression was higher in $\mathrm{Casp}^{-/}$mice. JNK activation leads to upregulation of several proapoptotic genes such as TNFa. ${ }^{35}$ A dual role for JNK in development of HCC has been proposed. $^{36}$ In hepatocytes, higher JNK activity prevents HCC development while JNK activation in non-parenchymal liver cells promotes HCC development. ${ }^{36}$ p53 is a well-known tumour suppressor that also regulates the DNA damage response. $^{37}$ DEN-injected WT mice showed a significant upregulation of total p53 protein and p53 expression (Supplementary Figure $6 \mathrm{~b}$ ). On the other hand, $m d m 2$ was reduced in DEN-injected Casp2 $^{-1}$ mice (Supplementary Figure 6c). As $\mathrm{mdm} 2$ is a target of $\mathrm{p} 53,{ }^{38}$ reduced gene expression in Casp2 $^{-1-}$ mice may be a consequence of failure of p53 activation in this group. Our immunoblot data indicated increased p53 and p21 protein levels in DEN-injected Casp $^{-/-}$mice. While no change in protein levels of PUMA, another p53 target that mediates DNA damage was observed, following DEN treatment control Casp2 ${ }^{-1}$ mice had elevated puma gene expression (Supplementary Figure 6d), which correlates with the observations that DNA damage is already higher in ageing Casp2 $^{-1-}$ mice. $^{22}$ Levels of noxa, another proapoptotic BH3-only protein, remained unchanged (Supplementary Figure 6e).

Interestingly, we also observed that IL $1 \alpha$, IL $1 \beta$ and IL6 levels were higher in DEN-injected Casp2 $2^{-/-}$mice. Inflammation has a key role in various types of cancers. ${ }^{39,40}$ The classical liver inflammatory cytokines described in a number of HCC-linked liver inflammation models include IL6, TNF- $a$, IL $1 a$ and IL $1 \beta .^{40,41}$ Several studies have reported higher IL6 levels in cases of HCC. ${ }^{42,43}$ DEN exposure promotes production of IL6 in Kupffer cells and stimulates tumour growth. Male mice have higher IL6 levels compared with females due to oestrogen-mediated inhibition reflecting the lower incidence of DEN-induced $\mathrm{HCC}$ in females ${ }^{44}$ and its importance in $\mathrm{HCC}$ progression can be realised from the fact that after ablation of IL6 male mice do not produce any more HCC than female mice. ${ }^{43,45}$

Previous studies have demonstrated that in two different models of DNA damage-driven mouse tumours, deficiency of caspase-2 had no significant effect. The authors found that lymphomagenesis in mice induced by repeated exposure to low-dose $\gamma$-irradiation, or formation of fibrosarcoma by injection of 3-methylcholanthrene (3-MC), a carcinogen forming bulky adducts with DNA, were similar in WT and Casp2-/mice. ${ }^{46}$ These data suggested that tumour suppression by caspase-2 is not involved in DNA damage-induced tumourigenesis. Our data on the other hand suggest that caspase-2 is a strong suppressor of DEN-induced HCC. Although it remains unclear why suppressor effects of caspase-2 are so vastly different in these models of tumourigenesis, it is possible that different mechanisms of tumourigenesis ( $\mathrm{HCC}$ versus lymphomagenesis and fibrosarcoma) contribute to differences in DNA damage response. For example, in addition to DNA damage, increased inflammatory and compensatory proliferation responses also have important roles in HCC, but may have limited roles in $\gamma$-irradiationinduced lymphomagenesis and 3-MC-dependent fibrosarcoma formation. Further studies will be required to fully understand the tumour suppressive effects of caspase-2 in 
a

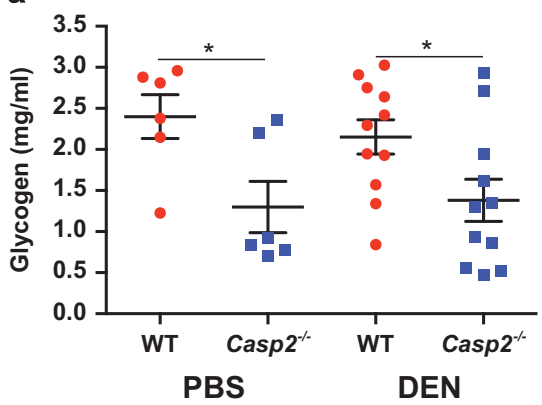

b

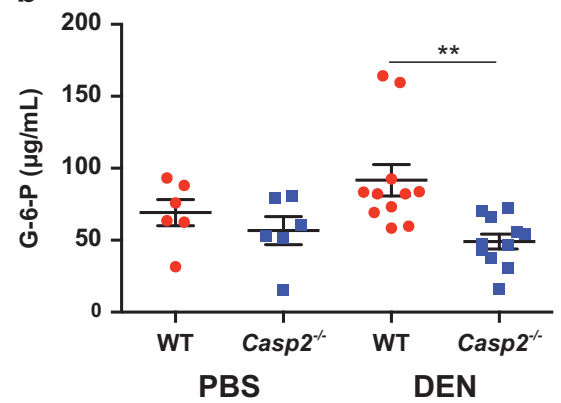

C

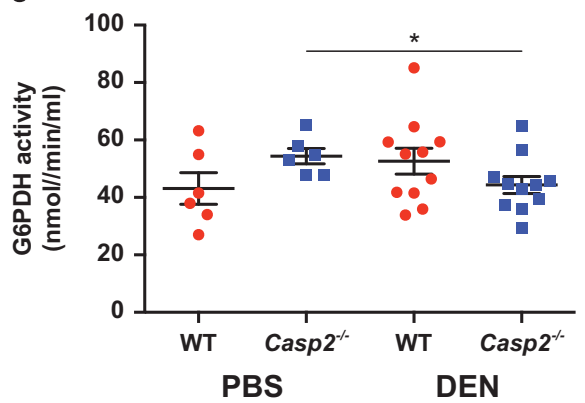

d

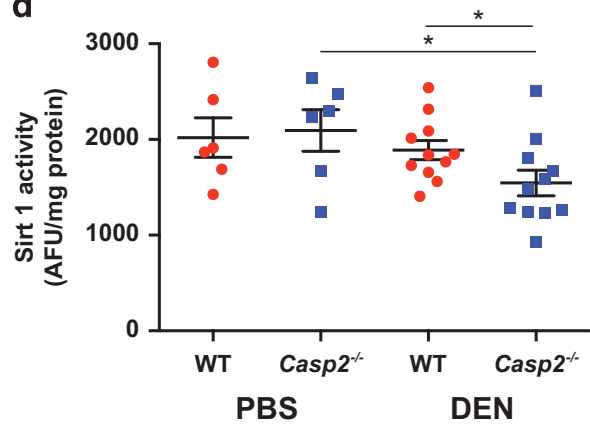

e

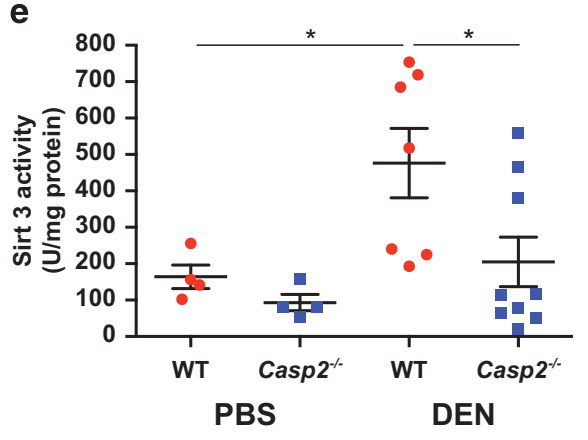

DEN

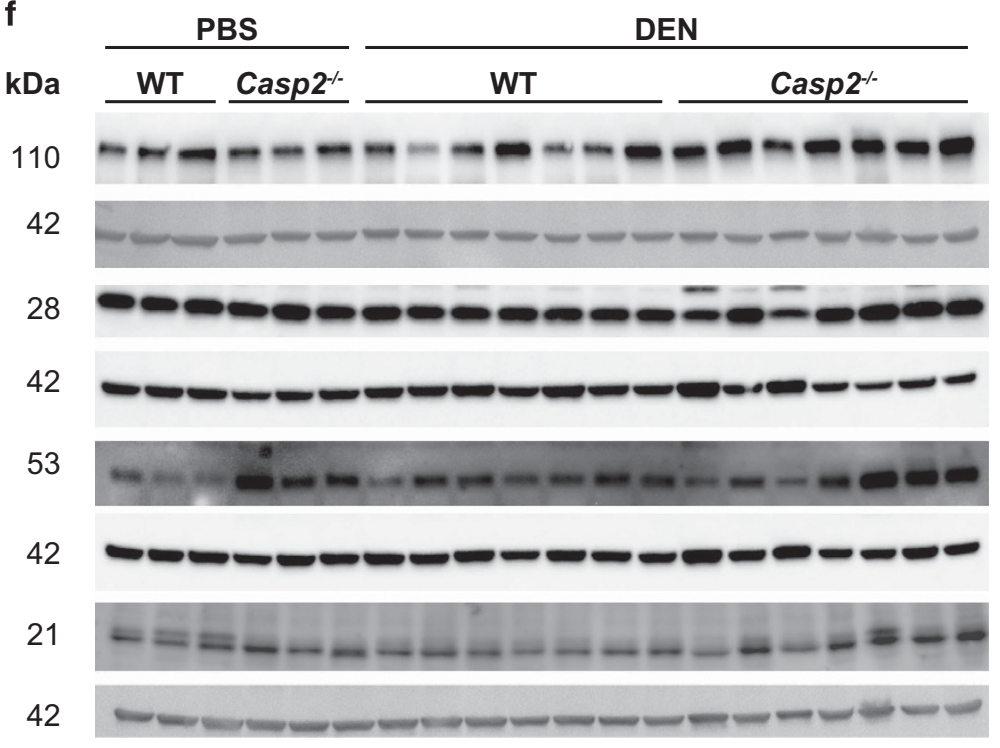

Sirt1

$\beta$-actin

Sirt3

$\beta$-actin

p53

$\beta$-actin

p21

$\beta$-actin

Figure 5 Metabolic state of Casp2 $2^{-1}$ mice favours tumour progression. Reduced (a) glycogen levels, (b) glucose-6-phosphate levels and (c) G6PDH activity in DEN-injected Casp2 $^{-/-}$mice. Decrease in Sirt1 (d) and Sirt3 (e) activities in DEN-injected Casp2 ${ }^{--}$mice liver 10 months after PBS/DEN administration. Values are given as mean \pm S.E.M. $(n=6$, PBS and $n=11, \mathrm{DEN})$. Statistics were performed using Student's $t$-test: ${ }^{*} P<0.05$ and ${ }^{*} P<0.01$. (f) Immunoblot analysis showing increased Sirt1 protein expression in DEN-injected Casp2 ${ }^{-/-}$mice. Upregulation of p53 and its downstream effector p21 was also observed

HCC and whether caspase-2 acts in more than one pathway in hepatocytes to limit DEN-induced carcinogenesis.

\section{Materials and Methods}

Mice. Male WT and Casp2 ${ }^{-/}$mice on a C57BL/6J background ${ }^{47}$ were used for all experimental studies. All animals were maintained in specific pathogen-free conditions in a 12-h/12-h light/dark cycle and treated in accordance with protocols approved by the SA Pathology/Central Northern Adelaide Health Services Animal Ethics Committee. To induce liver cancer, 15-day-old male pups were injected i.p. with $25 \mathrm{mg} / \mathrm{kg}$ bodyweight DEN (Sigma-Aldrich, St. Louis, MO, USA) and controls were injected with PBS. Mice were kept for 10 months after which they were humanely killed and blood and tissues collected. Acute effects of DEN were assessed in 6- to 7-week-old male mice injected i.p. with $100 \mathrm{mg} / \mathrm{kg}$ bodyweight DEN. Mice were humanely killed and tissues collected 24 and $48 \mathrm{~h}$ post injection.

Serum analysis and ELISA. Liver function tests (ALT, AST, LDH, ALP activity), triglycerides, cholesterol, $\mathrm{HDL}$ and LDL were determined in the serum by automated analysis (SA Pathology, Adelaide, SA, Australia). IL6 was measured in mice serum using the mouse IL6 ELISA kit (eBioscience Inc., San Diego, CA, USA), $\operatorname{TNF} \alpha$, IL $1 \alpha$ and IL $1 \beta$ were measured using commercially available mouse DuoSet ELISA kits (R\&D Systems, Minneapolis, MN, USA). 
a

$24 \mathrm{~h}$

$48 \mathrm{~h}$
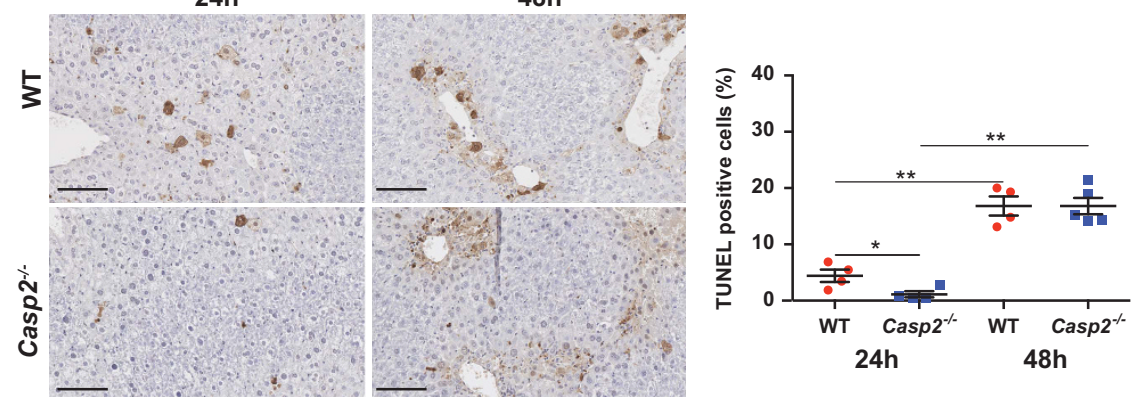

b

$24 \mathrm{~h}$

$48 \mathrm{~h}$
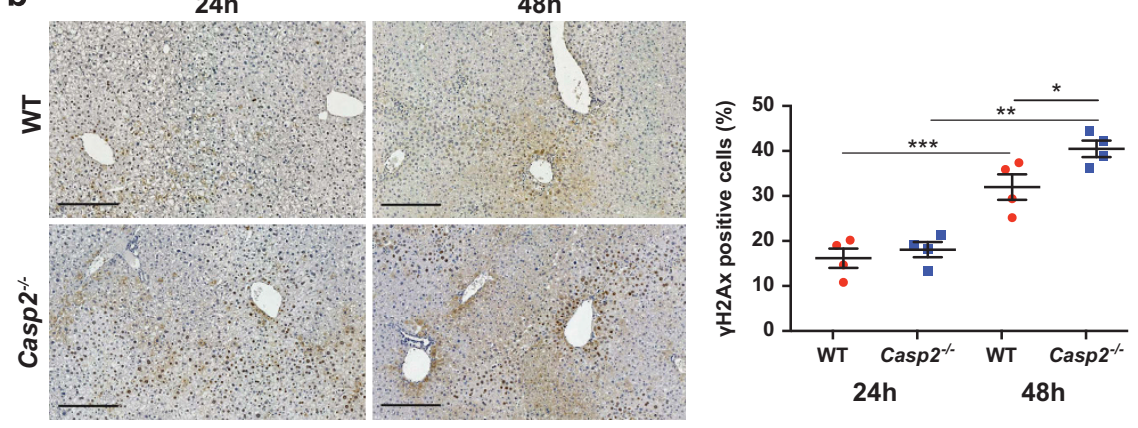

C

24h

48h
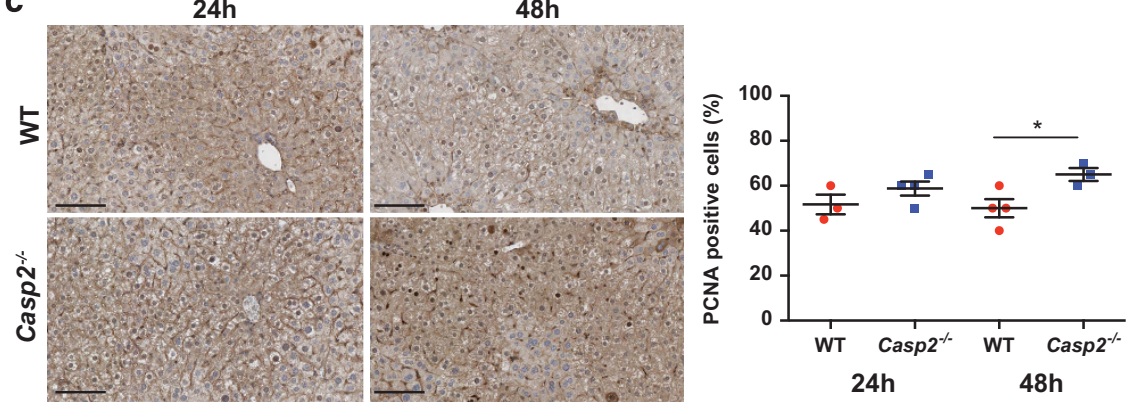

d
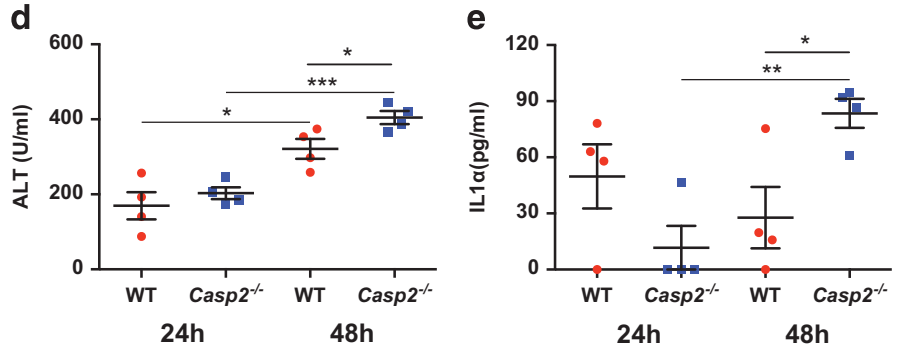

f

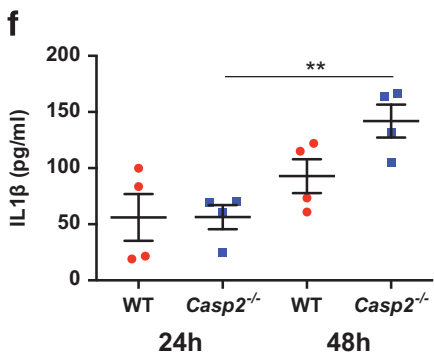

g

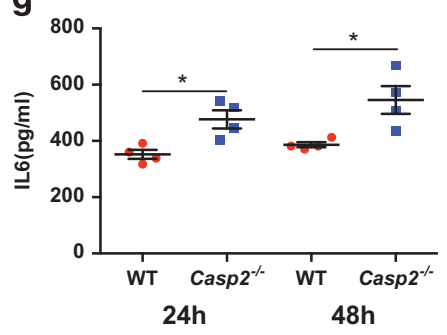


Figure 6 Acute response to DEN-induced liver damage in Casp2 ${ }^{-1}$ mice. (a) Representative images of cell death (TUNEL) 24 and $48 \mathrm{~h}$ after $100 \mathrm{mg} / \mathrm{kg} \mathrm{bodyweight} \mathrm{DEN}$ injection in 6- to 7-week-old mice. TUNEL-positive hepatocytes were few initially at $24 \mathrm{~h}$, but increased at $48 \mathrm{~h}$ and comparable between the two groups as quantitated on the right. Scale bar represents $100 \mu \mathrm{m}$. (b) Immunohistochemical localisation for $\gamma \mathrm{H} 2 \mathrm{Ax}$. Higher frequency of positive hepatocytes was observed in Casp2 ${ }^{-1}$ mice $48 \mathrm{~h}$ after acute DEN treatment. Scale bar represents $250 \mu \mathrm{m}$. (c) Immunohistochemical staining for PCNA and quantitation of PCNA-positive cells (right) showed a significant increase in proliferating cell number in Casp2 ${ }^{-1}$ mice $48 \mathrm{~h}$ after DEN exposure. Scale bar represents $100 \mu \mathrm{m}$. Increased serum (d) ALT, (e) IL1 $\alpha$, (f) IL1 $\beta$ and (g) IL6 after $48 \mathrm{~h} \mathrm{DEN} \mathrm{injection.} \mathrm{Data} \mathrm{are}$ shown as mean \pm S.E.M. $(n=4)$. Statistics were performed using Student's $t$-test: ${ }^{*} P<0.05,{ }^{* \star} P<0.01$ and ${ }^{* \star *} P<0.001$

Measurement of oxidative damage to protein, lipids and DNA. Protein, lipid and DNA oxidation was quantified using commercially available Protein Carbonyl Colorimetric Assay, TBARS Assay and 8-OHdG E1A Kits (Cayman Chemical, Ann Arbour, MI, USA) according to the manufacturer's instructions.

Measurement of liver metabolites and Sirt1 and Sirt3 activities. Glucose-6-phosphate, glycogen and glucose-6-phosphate dehydrogenase activities were measured in liver tissue homogenates using commercially available assay kits (Sigma; BioVision, Milpitas, CA, USA). Sirt1 and Sirt3 enzymatic activities were measured in liver tissue homogenates using the commercially available SIRT1 Fluorometric Kit (Enzo Life Sciences, Plymouth Meeting, PA, USA) and SIRT3 Direct Fluorescent Screening Assay Kit (Cayman Chemical, Ann Arbour, MI, USA) according to the manufacturer's instructions.

Histology and TUNEL. Liver tissue was fixed in $10 \%$ formalin for $24 \mathrm{~h}$, embedded in paraffin, sectioned $(7 \mu \mathrm{m})$ and stained with haematoxylin and eosin. Detection of apoptotic cells by TUNEL was performed on formalin-fixed, paraffinembedded liver sections using the ApopTag Peroxidase In Situ Apoptosis Detection kit (Millipore, Billerica, MA, USA) according to the manufacturer's instructions. Digital images were acquired by using a NanoZoomer (Hamamatsu Photonics, Hamamatsu City, Shizuoka Pref., Japan).

Immunohistochemistry. For immunohistochemical localisation studies, formalin-fixed, paraffin-embedded liver sections were deparaffinised in xylene and rehydrated in graded ethanol series. Endogenous peroxidase activity was blocked with $3 \%$ (vol/vol) $\mathrm{H}_{2} \mathrm{O}_{2} /$ PBS solution. Antigen retrieval was performed by sub-boiling the sections for 10 min in $0.1 \mathrm{M}$ Citrate Buffer Antigen Retrieval Solution (pH 6.0). Non-specific antibody binding was blocked using and $5 \%$ (vol/vol) FBS/PBS solution with Tween-20 for $30 \mathrm{~min}$. Tissue sections were incubated with anti-cleaved caspase-3 (9664; Cell Signaling Technology, Beverly, MA, USA) diluted 1:200, antiglypican3 (ab66596; Abcam, Cambridge, MA, USA) diluted 1:200, anti-PCNA (clone PC10; Cell Signaling Technology) diluted 1:250 and anti-phospho histone $\gamma \mathrm{H} 2 \mathrm{AX}$ (Ser139) (Cell Signaling) primary antibody diluted 1:100 in blocking solution overnight at $4{ }^{\circ} \mathrm{C}$. Tissue sections were sequentially incubated with anti-mouse or anti-rabbit biotinylated secondary antibody diluted 1:250 in blocking solution (GE Healthcare, Waukesha, WI, USA) and Avidin/Biotin Complex reagent (VectaStain ABC kit, Vector Labs, Burlingame, CA, USA) at room temperature. Peroxidase substrate (3,3'-diaminobenzidine) was added for colour development, followed by counterstaining with Mayer's haematoxylin solution (Sigma-Aldrich). Tissue sections were then dehydrated in graded ethanol series and coverslips mounted by using DePex mounting media (Sigma-Aldrich). Cells with positive staining were scored in at least five fields of view and reported as mean \pm S.E.M. Three or more mice were used in each group.

Immunoblotting. Liver tissues were homogenised in RIPA lysis buffer containing $50 \mathrm{mM}$ Tris- $\mathrm{HCl}$ (pH 7.4), $150 \mathrm{mM} \mathrm{NaCl}, 2 \mathrm{mM}$ EGTA, 2 mM EDTA, $25 \mathrm{mM}$ sodium fluoride, $25 \mathrm{mM} \beta$-glycerophosphate, $0.1 \mathrm{mM}$ sodium orthovanadate, $0.1 \mathrm{mM}$ PMSF, $0.2 \%$ Triton X-100, 0.3\% Nonidet P-40 and protease inhibitors (Roche Diagnostics, Basel, Switzerland) and phosphatase inhibitors (Thermo Fisher Scientific, Rockford, IL, USA). Homogenates were further treated by three freeze/thawed cycles in liquid nitrogen, clarified by centrifugation at $16000 \times g$ and protein concentration determined by the BCA quantification (Pierce, Thermo Fisher Scientific). In all, $40 \mu \mathrm{g}$ of lysates was resolved by SDS-PAGE, transferred onto PVDF membrane and probed for the specified antibody for $2 \mathrm{~h}$ at room temperature or overnight at $4{ }^{\circ} \mathrm{C}$. Secondary antibodies, conjugated with alkaline phosphatase (AP; Millipore), horse-radish peroxidase (HRP; GE Healthcare, Waukesha, WI, USA) or Cy5 (GE Healthcare), were incubated at room temperature for $1 \mathrm{~h}$. Proteins were visualised using ECF (Amersham, Little Chalfont, UK) or enhanced chemiluminescence (SuperSignal West Femto Maximum Sensitivity Substrate; Thermo Fisher Scientific). Membranes were immuno-blotted with the following antibodies: p44/42 MAPK (Erk1/2) (137F5), phospho-p44/42 MAPK (Erk1/2) (Thr202/Tyr204) (D13.14.4E), JNK (2C6), phosphoSAPK/JNK (Thr183/Tyr185) (81E11), cleaved caspase-3 (9664), caspase-3 (8G10), p53 (IC12), Sirt1 (2028), Sirt3 (D22A3), GAPDH (14C10) (Cell Signalling Technology, Beverly, MA, USA), p21 (clone SX118, BD Biosciences, Franklin Lakes, NJ, USA), caspase-2 (clone 11B4; Millipore), $\beta$-actin (AC15; Sigma-Aldrich) and PUMA (ab9643) (Abcam).

Quantitative PCR analysis. Total RNA was isolated from MEFs using TRIzol reagent (Invitrogen, Carlsbad, CA, USA) and cDNA synthesised using oligo-dT primers and High Capacity cDNA reverse transcription kit (Applied Biosciences, Foster City, CA, USA). Real-time PCR was performed on a Rotor-Gene 6000 (Qiagen, Valencia, CA, USA) using RT2 Real-Time SYBR Green/ROX PCR Master Mix (Qiagen) as per the manufacturer's instructions. The following primer sets were used for the amplification of mouse genes in qPCRs: $\beta$-catenin; 5'-CACCACAGCTCCTTCCCTGA-3', $5^{\prime}$ - C ATTGCATACTGCCCGTCAA-3', mdm2; 5'-GAAGGAGCACAGGAAAATATATGCA-3', 5'-GTCTGCTCTCACTCAGCGATGT-3', Trp53; 5'-CTCACTCCAGCTACCTGAAGA-3', 5'-AGAGGCAGTCAGTCAGTCTGAGTCA-3'; puma; 5'-ATGCCTGCCTCACCTTCAT CT-3', 5'-AGCACAGGATTCACAGTCTGGA-3'; noxa; 5'-ACTGTGGTTCTGGCGCAG AT-3', 5'-TTGAGCACACTCGTCCTTCAA-3', HGPRT; 5'-GAGAGCGTTGGGCTTACC TC-3', 5'-CTAATCACGACGCTGGGACT-3'.

Reactions were performed in triplicate and the mRNA expression levels normalised against the internal control gene HGPRT using the $2^{-\Delta \Delta C T}$ method.

Statistical analysis of data. Statistical analysis was performed using GraphPad Prism software (v 6.0, San Diego, CA, USA). Data are expressed as mean \pm S.D. or mean \pm S.E.M. Statistical significance was calculated with a Student's t-test. $P<0.05$ was considered to be significant.

\section{Conflict of Interest}

The authors declare no conflict of interest.

Acknowledgements. We thank Alyshea Collaco for injecting mice and the staff at the SA Pathology animal resource facility for maintaining the mouse strains. This work was supported by the National Health and Medical Research Council (NHMRC) of Australia project grant (1021456), a Cancer Council Collaborative Research Fellowship to LD, an NHMRC Early Career Research Fellowship to CW (1073771) and NHMRC Senior Principal Research Fellowships (1002863 and 1103006) to SK.

\section{Author contributions}

SS, LD and SK conceptualised and designed the study; SS, AN, JP, CW and NS performed experiments; SS, AN, LD, CW and SK analysed the data; JF helped with tumour histopathology analyses; SS, CW and SK wrote and revised the paper. All authors commented on the manuscript drafts and edited the text.

1. Puccini J, Dorstyn L, Kumar S. Caspase-2 as a tumour suppressor. Cell Death Differ 2013; 20: 1133-1139.

2. Puccini J, Shalini S, Voss AK, Gatei M, Wilson CH, Hiwase DK et al. Loss of caspase-2 augments lymphomagenesis and enhances genomic instability in Atm-deficient mice. Proc Natl Acad Sci USA 2013; 110: 19920-19925.

3. Ho LH, Taylor R, Dorstyn L, Cakouros D, Bouillet P, Kumar S. A tumor suppressor function for caspase-2. Proc Natl Acad Sci USA 2009; 106: 5336-5341.

4. Parsons MJ, McCormick L, Janke L, Howard A, Bouchier-Hayes L, Green DR. Genetic deletion of caspase-2 accelerates MMTV/c-neu-driven mammary carcinogenesis in mice. Cell Death Differ 2013; 20: 1174-1182.

5. Shalini S, Puccini J, Wilson CH, Finnie J, Dorstyn L, Kumar S. Caspase-2 protects against oxidative stress in vivo. Oncogene 2015; 34: 4995-5002.

6. Dorstyn L, Puccini J, Wilson CH, Shalini S, Nicola M, Moore S et al. Caspase-2 deficiency promotes aberrant DNA-damage response and genetic instability. Cell Death Differ 2012; 19: $1288-1298$. 
7. Kim JU, Shariff MIF, Crossey MME, Gomez-Romero M, Taylor-Robinson SD. Hepatocellular carcinoma: Review of disease and tumor biomarkers. World J Hepatol 2016; 8: 471-484.

8. Tang ZY. Hepatocellular carcinoma-cause, treatment and metastasis. World J Gastroenterol 2001; 7: 445-454.

9. Vesselinovitch SD, Koka M, Mihailovich N, Rao KV. Carcinogenicity of diethylnitrosamine in newborn, infant, and adult mice. J Cancer Res Clin Oncol 1984; 108: 60-65.

10. Verna L, Whysner J, Williams GM. N-nitrosodiethylamine mechanistic data and risk assessment: bioactivation, DNA-adduct formation, mutagenicity, and tumor initiation. Pharmacol Ther 1996; 71: 57-81.

11. Maeda S, Kamata $H$, Luo JL, Leffert $H$, Karin M. IKKbeta couples hepatocyte death to cytokine-driven compensatory proliferation that promotes chemical hepatocarcinogenesis. Cell 2005; 121: 977-990.

12. Wei JC, Meng FD, Qu K, Wang ZX, Wu QF, Zhang LQ et al. Sorafenib inhibits proliferation and invasion of human hepatocellular carcinoma cells via up-regulation of p53 and suppressing FoxM1. Acta Pharmacol Sin 2015; 36: 241-251.

13. Buitrago-Molina LE, Marhenke S, Longerich T, Sharma AD, Boukouris AE, Geffers R et al The degree of liver injury determines the role of p21 in liver regeneration and hepatocarcinogenesis in mice. Hepatology 2013; 58: 1143-1152.

14. Wree A, Johnson CD, Font-Burgada J, Eguchi A, Povero D, Karin M et al. Hepatocytespecific Bid depletion reduces tumor development by suppressing inflammation-related compensatory proliferation. Cell Death Differ 2015; 22: 1985-1994.

15. Qiu W, Wang X, Leibowtiz B, Yang W, Zhang L, Yu J. PUMA-mediated apoptosis drives chemical hepatocarcinogenesis in mice. Hepatology 2011; 54: 1249-1258.

16. Teoh N, Pyakurel P, Dan YY, Swisshelm K, Hou J, Mitchell $C$ et al. Induction of p53 renders ATM-deficient mice refractory to hepatocarcinogenesis. Gastroenterology 2010; 138 : 1155-1165, e1151-e1152.

17. Liedtke C, Zschemisch NH, Cohrs A, Roskams T, Borlak J, Manns MP et al. Silencing of caspase-8 in murine hepatocellular carcinomas is mediated via methylation of an essential promoter element. Gastroenterology 2005; 129: 1602-1615.

18. Bai L, Ni HM, Chen X, DiFrancesca D, Yin XM. Deletion of Bid impedes cell proliferation and hepatic carcinogenesis. Am J Pathol 2005; 166: 1523-1532.

19. Weber A, Boger R, Vick B, Urbanik T, Haybaeck J, Zoller S et al. Hepatocyte-specific deletion of the antiapoptotic protein myeloid cell leukemia-1 triggers proliferation and hepatocarcinogenesis in mice. Hepatology 2010; 51: 1226-1236.

20. Pierce RH, Vail ME, Ralph L, Campbell JS, Fausto N. Bcl-2 expression inhibits liver carcinogenesis and delays the development of proliferating foci. Am J Pathol 2002; 160: $1555-1560$.

21. Wilson $\mathrm{CH}$, Shalini S, Filipovska A, Richman TR, Davies S, Martin SD et al. Age-related proteostasis and metabolic alterations in Caspase-2-deficient mice. Cell Death Dis 2015; 6 : e1597.

22. Shalini S, Dorstyn L, Dawar S, Kumar S. Old, new and emerging functions of caspases. Cell Death Differ 2015; 22: 526-539.

23. Shalini S, Dorstyn L, Wilson C, Puccini J, Ho L, Kumar S. Impaired antioxidant defence and accumulation of oxidative stress in caspase-2-deficient mice. Cell Death Differ 2012; 19: 1370-1380.

24. Yang S, Chang C, Wei R, Shiue Y, Wang S, Yeh Y. Involvement of DNA damage response pathways in hepatocellular carcinoma. Bio Med Res Int 2014; ;2014: 153867.

25. Hacker HJ, Mtiro H, Bannasch P, Vesselinovitch SD. Histochemical profile of mouse hepatocellular adenomas and carcinomas induced by a single dose of diethylnitrosamine. Cancer Res 1991; 51: 1952-1958.
26. Schug TT, Li X. Sirtuin 1 in lipid metabolism and obesity. Ann Med 2011; 43: 198-211.

27. Garcia-Rodriguez JL, Barbier-Torres L, Fernandez-Alvarez S, Gutierrez-de Juan V, Monte MJ, Halilbasic E et al. SIRT1 controls liver regeneration by regulating bile acid metabolism through farnesoid $\mathrm{X}$ receptor and mammalian target of rapamycin signaling. Hepatology 2014; 59: 1972-1983.

28. Zhang YY, Zhou LM. Sirt3 inhibits hepatocellular carcinoma cell growth through reducing Mdm2-mediated p53 degradation. Biochem Biophys Res Commun 2012; 423: 26-31.

29. Farber E. Liver cell cancer: insights into the pathogenesis of hepatocellular carcinoma in humans from experimental hepatocarcinogenesis in the rat. Monogr Pathol 1987; 28: 199-222.

30. Kolaja KL, Klaunig JE. Vitamin E modulation of hepatic focal lesion growth in mice. Toxicol Appl Pharmacol 1997; 143: 380-387.

31. Valko M, Rhodes CJ, Moncol J, Izakovic M, Mazur M. Free radicals, metals and antioxidants in oxidative stress-induced cancer. Chem Biol Interact 2006; 160: 1-40.

32. Kawanishi S, Hiraku Y, Murata M, Oikawa S. The role of metals in site-specific DNA damage with reference to carcinogenesis. Free Radic Biol Med 2002; 32: 822-832.

33. Heindryckx F, Colle I, Van Vlierberghe $\mathrm{H}$. Experimental mouse models for hepatocellular carcinoma research. Int J Exp Pathol 2009; 90: 367-386.

34. Tao R, Coleman MC, Pennington JD, Ozden O, Park SH, Jiang H et al. Sirt3-mediated deacetylation of evolutionarily conserved lysine 122 regulates MnSOD activity in response to stress. Mol Cell 2010; 40: 893-904.

35. Dhanasekaran DN, Reddy EP. JNK signaling in apoptosis. Oncogene 2008; 27: 6245-6251.

36. Das M, Garlick DS, Greiner DL, Davis RJ. The role of JNK in the development of hepatocellular carcinoma. Genes Dev 2011; 25: 634-645.

37. Meek DW. Tumour suppression by p53: a role for the DNA damage response? Nat Rev Cancer 2009; 9: 714-723.

38. Wu X, Bayle JH, Olson D, Levine AJ. The p53-mdm-2 autoregulatory feedback loop. Genes Dev 1993; 7: 1126-1132.

39. deVisser KE, Coussens LM. The inflammatory tumor microenvironment and its impact on cancer development. Contrib Microbiol 2006; 13: 118-137.

40. Mantovani A, Allavena P, Sica A, Balkwill F. Cancer-related inflammation. Nature 2008; 454 : 436-444.

41. Grivennikov SI, Greten FR, Karin M. Immunity, inflammation, and cancer. Cell 2010; 140 : 883-899.

42. Grivennikov SI, Karin M. Dangerous liaisons: STAT3 and NF-kappaB collaboration and crosstalk in cancer. Cytokine Growth Factor Rev 2010; 21: 11-19.

43. Johnson C, Han Y, Hughart N, McCarra J, Alpini G, Meng F. Interleukin-6 and its receptor, key players in hepatobiliary inflammation and cancer. Trans/ Gastrointest Cancer 2012; 1: $58-70$.

44. Liu Y, Fuchs J, Li C, Lin J. IL-6, a risk factor for hepatocellular carcinoma: FLLL32 inhibits IL-6-induced STAT3 phosphorylation in human hepatocellular cancer cells. Cell Cycle 2010; 9: 3423-3427.

45. Naugler WE, Sakurai T, Kim S, Maeda S, Kim K, Elsharkawy AM et al. Gender disparity in liver cancer due to sex differences in MyD88-dependent IL-6 production. Science 2007; 317: 121-124.

46. Manzl C, Peintner L, Krumschnabel G, Bock F, Labi V, Drach M et al. PIDDosomeindependent tumor suppression by Caspase-2. Cell Death Diff 2012; 19: 1722-1732.

47. O'Reilly LA, Ekert P, Harvey N, Marsden V, Cullen L, Vaux DL et al. Caspase-2 is not required for thymocyte or neuronal apoptosis even though cleavage of caspase-2 is dependent on both Apaf-1 and caspase-9. Cell Death Differ 2002; 9: 832-841.

\section{Supplementary Information accompanies this paper on Cell Death and Differentiation website (http://www.nature.com/cdd)}

